\title{
Choosing the Partner in a Digital Fabrication Case
}

\section{A Escolha dos Parceiros em um Caso Fabricação Digital}

\author{
Elza Luli Miyasaka \\ Architecture and Urbanism Institute \\ University of São Paulo - IAUUSP - Brazil \\ University Center Barão de Mauá - UCBM - Brazil \\ elzamiyasaka@gmail.com
}

\section{Associate Prof. Ingrid Paoletti}

ABC Dept. Politecnico di Milano University - Italy

ingrid.paoletti@polimi.it

\author{
Associate Prof. Marcio Minto Fabricio \\ Architecture and Urbanism Institute \\ University of São Paulo - IAUUSP - Brazil \\ marcio@sc.usp.br
}

\begin{abstract}
This paper presents a partnership organization of several enterprises to build a pavilion in Expo 2015 . Cutting edge technology, cooperation and collaboration associated with communication systems are the key issues to success in a global market.
\end{abstract}

Keywords: Industry 4.0, Collaboration, Cooperation, Digital Fabrication, Civil Construction.

\section{Introduction}

The choice of the operators in a building process organization is as important as design, production and construction. This is due to the fact that in recent years in AEC (Architecture Engineering Construction) sector some firms have proposed complex buildings using affordable cutting edge technologies in terms of design, material, production and assembling i.e. digital fabrication. The organization that is usually used to build these projects include adding partnerships and collaboration endeavors with enterprises that have different skills and specializations. To that end, this paper discusses the various partnership choices across the world to construct the pavilion in EXPO Milan 2015.

Some authors believe we are in the $3^{\text {th }}$ Industrial Revolution; signing the $1^{\text {st }}$ revolution was held with hydraulic energy, the $2^{\text {nd }}$ with electricity, mass production (production line) and the electronics; and the current revolution as the informatics digital revolution. Some others consider that now it is the $4^{\text {th }}$ Industrial Revolution separating the electricity from electronics. However, all agree that we are in the beginning of a new revolution, thanks to the transformations associated to the digital technology in all aspects of society and economy. This actual context is characterized by various tools connected to the Internet including the possibility of advanced personalized customization, equipment and machines with high technology, and digital fabrication (Naboni \& Paoletti, 2015)); also a complex system related to production and market associated with real time cloud data storage Potti (2015).

Schwab (2016) points out 3 reasons that the last industrial revolution is underway: a. velocity: the new technology capable to interconnect the world; b. breadth and depth: leading the paradigm to change our way of life, the economy, the business society and individuality.

c. Impact on the system: transforming entire systems, across (and within) countries, companies, industries and society as a whole.

According to him, the Industry 4.0 is the possibility to produce new product processes, manufacturing systems and cooperation in a flexible way (Schwab, 2016, p. 71).

The cutting edge companies are using several strategies as: digital technology, cloud services, mobile access by apps, sensors in products and ecosystems, registered multiplication data, automated production robots, personalized ecommerce producing information trends, startup experiments, artificial intelligence and Nano connectors. The values and prices of goods are moving according to the activities associated with a smart way of producing and, services are focused on quality for customers, and efficient logistic maintenance of a competitive environment (Biase 2015).

To be part of this complex process building construction is essential to be associated with an integrated net of collaborators with skills on several disciplines to add each other with the same objective that in the end is to build the pavilion.

\subsection{The Industrial Context of Digital Fabrication}

The term Industry 4.0 was first used in Germany in 2011 to announce a government project to develop a high-tech digitalization of the manufacturing industry. Industry 4.0 is a digital industrial system, ecosystem of factories, machines and intelligent objects, capable of communicating and interacting with each other and with the customers. Innovation is the center issue and is based on robotics, nanotechnology and additive manufacturing. The digital transformation is seen in automation, availability of large data 
files, direct access to the client by internet and connectivity obtained through the internet. The most important is the paradigm shift: in the global era production is not centralized, but where the goods are consumed; it disseminates knowledge not the product; production is bottom up aggregating production functions to the artifact. Therefore, the production is based on a tripod (1) it is possible have personalized products, like clothing, food and medicine; (2) new machines analyze massive data sets comparing individual data and produce personal objects, and (3) in this personalized production, the customer is an actor and responsible for such decisions (Larizza, 2015).

The globalization theme can be discussed from many points of view, from ancient times, when the eastern commerce enriched with oriental goods, or in the $20^{\text {th }}$ century, with the dissemination of cultures and customs or in the present days with communication system creating a World Wide Web in real-time connectivity. The definition of globalization as "...a condition characterized by the presence a single sociopolitical space on a planetary scale" was introduced by Batelson (2010), and it fits this real concept very well. As expected, the civil construction is also influenced by the changes in everyday situations and; the participation of many actors and enterprises from different places in the construction of buildings is an example of the reality of this globalization.

Drewer (2001) describes that since the late 1960s global construction activities have become more concentrated within the richer industrialized countries. Furthermore, during this period an international construction system has emerged that is dominated by practices, contractors and material producers as well as by technologies and procedures that originated in these same countries. Consequently, the richer countries dominate somewhere between 80 and $90 \%$ of all global construction activities, either directly or indirectly through their contractors, design consultants and material producers. One explanation for their dominant role is their collective economic strengths; however, it is also due to the technologies now used internationally to carry out a complex array of different building and civil engineering projects.

The construction sector is directly related with the development of industries and its economic role. Han et al. (2010) points out that the amount of construction in the world is distributed in the global market as follows: Asia $37 \%$, Europe $31 \%$ and North America $23 \%$. In terms of volume, the U.S. has the biggest participation, followed by Japan, China and the UK.

The AEC market has lived through contemporaneous changes and the challenges it faces are: (1) clients are analyzing the additional services offered, such as technology transfer and risks; (2) more capabilities and resources are required with private investments, expanding large projects as integrated schemes; (3) the financing programs are fundamental to increase opportunities in the construction market; (4) there are several risks involving costs, equipment and cultural differences. To address these issues and to remain competitive and maintain their competitive edge, the contractors have implemented partnerships (Han et al., 2010),
Cooperation-based alliance with various collaborators is a complex undertaking in civil construction. Cheah, Garvin, Miller (2004) discuss strategies of global construction firms, citing that success is derived from different modes of operational, financial, technological and human-related conditions. For example:

... the success of Japanese contractors is attributed to their technological superiority, financial capacity, skills of forming strategic alliance with host governments and local firms (Han et all, 2014, p. 736).

In this context of contemporary Industrial Revolution, the principal activities focus on industries and services, as Perissich (2016) explains that the main determining growth factors are: increase outsourcing with their own competency; the trend to sell service by industries, not the commodity or product and a general manufacturing growth trend. The term Business Services are characterized as net enterprises with capacities and competencies to better improve a product for clients, and net organizations are able to provide solutions, results and create new services collectively, with the collaboration of large and small enterprises.

In the context and circumstances of this era the efforts are focused on the net market tendency, where society behavior is changing and it is central to be associated with partners that have different skills to expand competitiveness. As analyzed by Comu, Taylor, Messner (2012), the reasons behind these associations are to reduce costs, for customers and projects, better service, to increase quality and shorter project cycle times. Also included are hybrid business arrangements with collaborative combinations in cutting-edge technology and competitiveness. The complexity of projects reinforces the need for different and specialized suppliers from several countries.

The collaboration process considers the participation of two or more firms or persons, working together, sharing knowledge, learning and building consensus to reach the same goal. Within the benefits are, "...improved access to information and people across the enterprise, on-demand availability of data for accelerated decision making, enterprise-wide sharing of knowledge and resources, reduced error rates..." Chiprianov (2014). Also many authors agree with "...better value, time savings, better quality, improved profit margins, and the ability to handle risks both upstream and downstream in relationships..." (Wood and Ellis, 2005; Ibem, Laryea 2014; Li et al. 2012). On the other hand, these networks also "...(1) benefit the entire industry (2) Partnering increases profits by enhancing the relationship between main contractors and subcontractors (3) Current management practices do not support cooperative networking" (Wood and Ellis, 2005).

All these contexts would not be possible without the advance of currently available technology tools, as described earlier. The evolution of Digital Tools is particularly recognized with the replacement of analogue information for digital ones, before this phase, the information was electro-mechanical, such as telegraphs, telephone, radio and TV. And further back in time the invention of the Morse code manual transmission which used a code system. Digital Tools are used for the "integration, collaboration and coordination of 
work process with capabilities to support processing, communication and integration functions" (Ibem, Laryea 2014).

Information is the main managing object and concerns all participants in the civil construction supply chain. Types of workflow communication shows exchange projects to collaborate, share, or generate components. This kind of electronic information exchange is called e-Business (Schneider, 2003). Coordinating the information flow becomes easier using technology to acquire information, such as project management, even more so if the available existing software is considered.

Computational methods aimed at facilitating collaboration have focused primarily on assisting the communicative aspects of collaboration in $A / E / C$. These have resulted, on the one hand, in Building Information Models (BIM) that, in addition to the product's geometry, also stores many of its other attributes and can convey much more information than traditional drawings and models can. On the other hand, they have resulted in computational systems that can facilitate the management of the design and construction processes by tracking drawings, managing their different versions, and coordinating concurrent access to the information (Kalay, 2006, p. 360).

BIM software system is the platform used to manage production and supplies on real-time schedule, an information system witch aggregates different disciplines at the same object and works as a competent complex visual modeling.

Another aspect is the procurement associated with technologies. Procurement in construction is a process composed of steps and activities ${ }^{1}$ usually associated with a building construction focused on managing supplies, cost and agreed terms to a contractor client along the progress of construction (Ibem, Laryea 2014). Technologies associated to procurement are used for capturing, processing, storage and communication technologies.

The association of many work contractors, each one with different skills and individually specialized compose the team of constructors. Rahman et al. (2014) identify six perspectives of contractors regarding the importance of collaboration in the construction supply chain:

1 - CLIENT'S DECISION ABOUT THE ACQUISITION STRATEGY FOR A FACILITY E.G. BUILDING - DETERMINATION OF THE MOST APPROPRIATE WAY TO ORGANIZE THE PROCUREMENT PROCESS - ORGANIZATION OF THE PROJECT TEAM • CONSTRUCTION PRODUCTION PROCESS - APPOINTMENT OF A PROJECT MANAGER - DESIGN DEVELOPMENT PROCESS - SELECTION OF MULTIDISCIPLINARY PROJECT TEAM - DEVELOPING THE DESIGN • CONSTRUCTION PRODUCTION PROCESS - DESIGN - PREPARATION OF CONSTRUCTION DOCUMENTS • CONSTRUCTION CONTRACT ADMINISTRATION • ESTABLISHMENT OF CLIENT'S OBJECTIVES - SELECTION AND APPOINTMENT OF DESIGNER • Preparation of outline design and COSt estimates - Selection of CONSTRUCTOR - START CONSTRUCTION • NEED IDENTIFICATION • SPECIFICATION OF REQUIREMENT - TENDER PROCESS AND AWARD OF CONTRACT - MANAGEMENT OF CONTRACT - TERMINATION OF CONTRACT • ESTABLISHMENT OF WHAT IS TO BE PROCURED • DECIDING ON PROCUREMENT STRATEGIES • SOLICITING FOR TENDER OFFERS • EVALUATING TENDER OFFERS - AWARDING OF CONTRACTS; AND - ADMINISTRATING CONTRACTS TO ENSURE THAT THEY COMPLY WITH REQUIREMENTS - SETTING UP OF THE PROJECT DEFINING THE PROJECT - ASSEMBLAGE OF TEAM - DESIGN OF PROJECT • TENDERING - CONSTRUCTION; - POST PROJECT EVALUATION AND POST OCCUPANCY EVALUATION (IBEM, LARYEA, 2014, P. 19) (i) collaboration encourages teamwork; (ii) similar racial collaboration develops cooperation between team members; (iii) stimulate information sharing; (iv) improves quality and timely project completion; (v) enhance service quality; and (vi) better communication among project members (Rahman et al, 2014, p. 418).

And Finally, the success of a partnership requires "commitment, evaluation, equity, common goals, communication, trust, and cooperation" (Eom Shin-Jo, 2014, p. 1953) from all the collaborators, working to find better solutions for the problems that appear in the process to build the construction.

\section{Methodology Procedure for the Case Study}

The data collected are based on original documents such as plants, sections, elevations, sketches and pictures, also analyzed are the communication documents, for example several reports, managing documents, organograms, chronograms, procurement documents, and others. Furthermore, the authors carried out semi-structured interviews with key actors of team work who participated in the construction project; they are design managers, project managers, site managers and etc.

The visits to the site were periodically, also visits to the participating GRC panels and factories of structures were done. These visits included talking with the design manager, design team, analyzing manufacturing plan, production and logistic to gather the questions that involve the construction project.

With the data collection, the documents are input in a database, categorized, tabulated and charted to be analyzed. All information are crossed-referenced and triangulated to construct a consistent theoretical base. Although all data are to discuss one single case in this paper, it constitutes the information that will be aggregated to other cases within the same point of view in order to carry out the content analysis and generalization in future papers.

To process the analysis included describing the workflow and discussing the participation of each firm. Cooperation and collaboration is revised according to the qualification and expertise of the participants. The paper analyzes the data with the specific aim to understand how to choose a partner in a digital manufacturing case.

\section{The Project}

The pavilion was for Expo Milan 2015, opened from May to October 2015, with the goal of disseminating the culture and customs of the United Arab Emirates (UAE), the exhibition theme;

Feeding the Planet, Energy for Life, in terms of content and approach, thereby maximizing their participation in the Exposition as an opportunity to showcase their own particular points of excellence ${ }^{2}$ (Expo 2015 S.p.A. - Milano, 2012).

2HTTP://WWW.CZEXPO.COM/FILES/EXPO-MILANO-THEME-GUIDE.PDF. ACCESSED: MAY 29, 2016. 
The project design is by Foster and Partners and is one of the largest pavilions in the Expo, 5,000 $\mathrm{m}^{2}$ and 3 floor levels divided in four parts: (1) the entrance is a Canyon that guide the visitor to the auditorium; (2) Block $B$ is the theater which featured the main show, (3) Block A held the offices, staff rooms and post show: a second theater with innovative 3D projection technology; and (4) Block C which held the facilities and restaurants.

The structure of the pavilion is a steel frame covered with Glassfiber Reinforced Concrete (GRC) panels, a common material in civil construction used in a different way. The texture of all panels had ripples that are inspired on the desert's sand pattern, and the shape of the canyon panels are curved, giving a similar effect as standing in the middle of this canyon-like scenario.

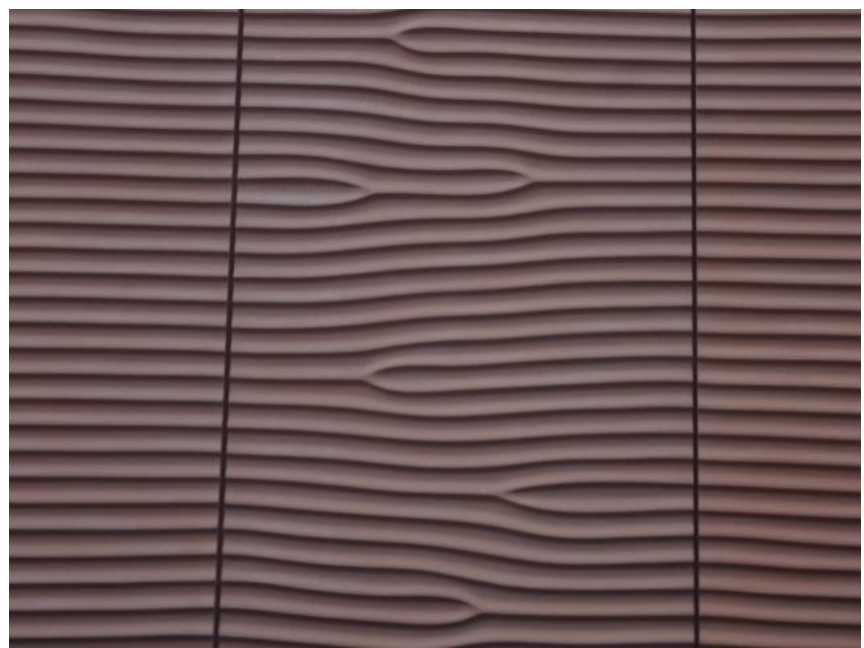

Figure 1: Panels pattern texture inspired on desert sand waves. Photo: author. Date: 2016.

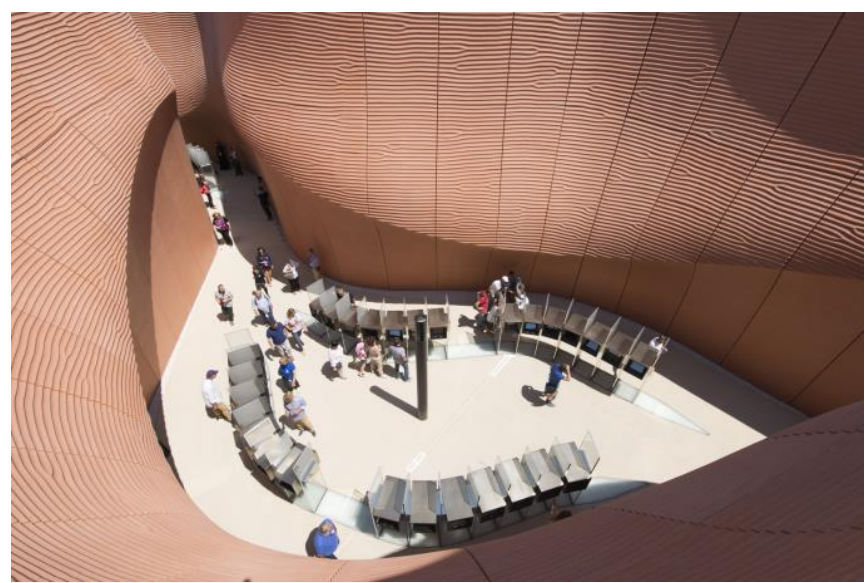

Figure 2: Canyon. Photo Nigel Young + Foster \& Partners.

This is a complex building with many details and solutions, from the architecture design, interactive exhibitions, structure, substructure, different kind of curved and flat panels, junctions, technological 3D projections, extensive program, facilities, etc.

The construction project required 263 days from the design concept to the end of construction, with necessary intensive work from many collaborators, tenders, managers in different levels, developing details, logistics, analyzing the best way to assemble, approving certificates, making mockups, testing materials and its behaviors. This work results in 129,426 man hours, that means in this complex construction of $5,000 \mathrm{~m}^{2}$, the average of man work per day is 492 man hour of high quality specialization to produce this building.

Another data is the quantity of drawings needed to have all issues developed. It was 1148 shop drawings produced to this project. As the principal document for communication with all collaborators is important to mention that, as it will be discussed below, BIM information system, internet and the cloud system is fundamental to manage and exchange data with all participators, witch would not be possible with companies in different places in the world.

The 930 GRC panels are produced in Hong Kong, a resistant but fragile material that need special care to be transported. There was 18 shipments from Hong Kong to Italy with complex planned logistic, due the panels needed to be assembled according to their departure. These small data shows the complexity of the construction process and how several companies need to be organized and work as an orchestra.

\section{Work Process}

\subsection{Team}

This step analyzes the enterprises that are in the development and construction process. In the prequalification, the companies had to respond an extensive application form divided in: (1) basic information: name, address, phone, professional in charge; (2) Status: nature of the company, date when activities began, if it is a lead company; (3) financial information: turnover, forecasted turnover, audited accounts, group structure, certificate numbers; (4) Company Project Structure \& Resources: number of employees, staff details, quantities, qualifications, managers, organogram. (5) Background on similar works and, (6) Client references.

The team was integrated by six main groups, as shown below, 


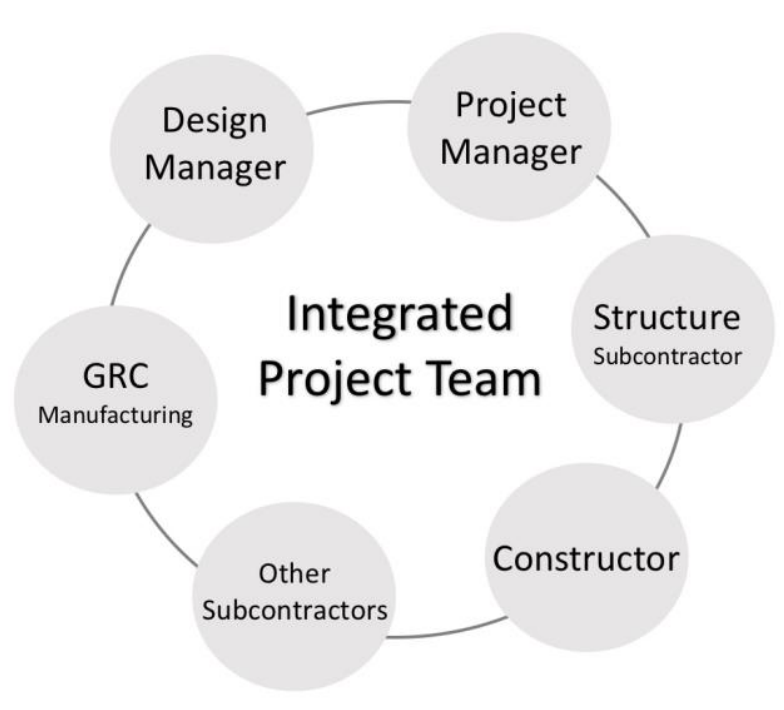

Figure 2: Integrate team for UAE Pavilion. Font: Project Manager diagram. Date: June, 2016.

Design Manager: A United Kingdom firm, Fraser and Randal, is directly connected with the client and architectural design team. This enterprise has extensive experience managing complex projects; contents such as graphics, media, interaction and environment; design, clarifying, and structuring, organizing, briefing and feedback; procurement, searching better suppliers; managing construction; cost and construction design. Here, they are responsible for Manager, monitoring the entire process, qualifying the partners, supervising costs and evaluation process and quality survey, organizing meetings, communications, qualifications of suppliers, revision and approval of all drawings, deadlines and services.

Project Manager - was composed of 2 firms: The first one, A\&A Company is based in South Korea since 2000, offering solutions and executions of marketing methods, especially in the information and communication area. Its expertise in elaboration and development of brands; applications; production, execution and input of market goods (Project Manager). In pavilion project they are also responsible for the project manager and construction consultant, answering to the specifics projects and logistics. Also, studying construction methods and inspection, and preparing timely reports and process reports.

The second one, Rimond is an Italian firm working with consulting, project managing and site manager. Their expertise is in engineering, procurement and developing infra-structure. In the UAE pavilion they conducted the compliance projects, such as sustainable issues, local licenses, verification and studying construction methods, security, hydraulics, lighting, ventilation system, and accessibility. They are also responsible for procurement, technical manager, planning and supervision of the construction site. Furthermore, they had the university as partnership in this project, doing clash detection on BIM information system and using the labs tests and simulations.
Constructor: Tecton is an Italian firm, works with the Construction of several buildings; such as churches, schools, public and financed; residential, commercial, interiors, restoration, archeology, historical buildings and monuments. In this building they are responsible for the main constructors, such as foundations, slabs, facilities, environmental and logistics manager, security and health quality and also the coordination of documentation control. At the site, they are also in charge of the project supervisor, project manager, procurement issues, architecture, engineering, the productions of subcontractors and to solve urban-related problems. Moreover, working at the site are the structure firm in charge of assembling the steel frame of the main structure and the GRC firm that assembled the construction panels.

- Steel Frame Factory: Stahbau Picler is an Italian factory, in the market since 1970, their expertise is in design, manufacturing and building steel frame structures and curtain wall systems. In this project the main structure was a steel frame; a complex structure associated with the substructure of the GRC panels.

- GRC Factory: Canbuild is from Hong Kong since 1992, specialized in managing and civil engineering, they have extensive experience in manufacturing pre-cast components. In this project they built all GRC panels with different textures. Also, the several curved panels, corner panels and small panels, the substructure was produced and aggregated on the panels by this company.

The option of choosing the firms is an example of Business Service, linked with capacities, competencies, qualification of work in specific discipline, experience, other works at similar buildings, technology used, but also on confidence and relationship. Some points are facilitated with the location of the companies, as local solutions with certification approval, laws, cultural logic and language. This net organization with several partnerships from different expertise and places improve better solutions on solve problems, using high tech equipment and machines to provide the complex system production of this building, as facilities, structure, engineering issues, panels, interior, etc.

\subsection{WorkFlow}

This pavilion was contracted by the United Arab Emirates MC (National Media Council) that selected a specific team to follow the project. The firm responsible for the architecture design executed the central architectural concept. The simplified diagram below shows how each workflow is organized. There are 3 main groups: $1^{\text {st }}$ Group. Main Managers including the client, architecture firm and main managers; $2^{\text {nd }}$ Group. Design Manager, including the architecture and coordinating engineers and; $3^{\text {rd }}$ Group. Site Managers and Manufacturing Manager.

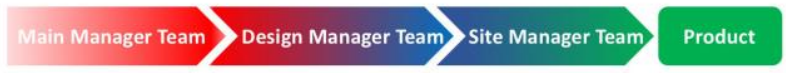

Figure 3: General Scheme of work process 
The Main Manager Team includes the contractor that selected a Project group to follow the main design team, the English Architectural Design and the United Kingdom Main Manager Team, two offices under these managed all functions, such as engineering, architectural details of BIM modeling, and matters related to the construction site.

Moreover, 4 countries were represented in this organogram, the client from UAE, the United Kingdom in charge of the project and the main manager; Italy had the commitment project manager and technical drawings coordination and; Korea was in charge of project manager and manufacturing components.

The simplified organogram below shows the workflow organization to build the pavilion. As discussed before, it shows the responsibilities of the tree main groups.

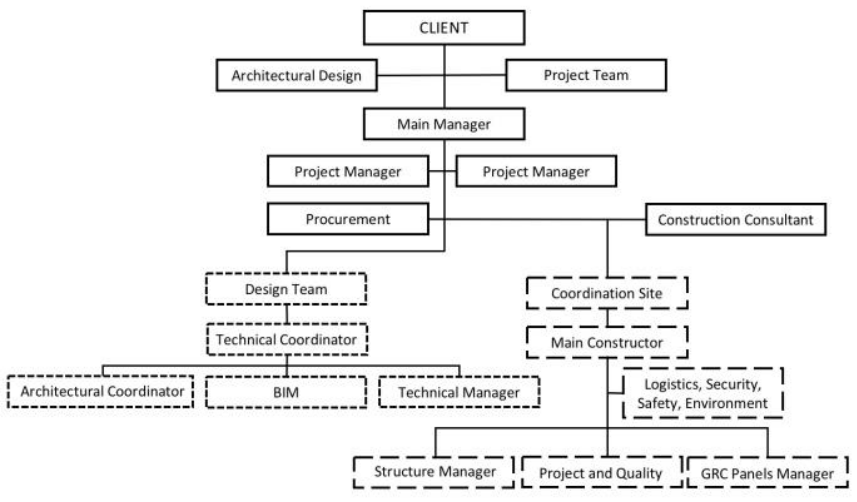

Figure 4: Organogram team workers. Font: author, date: 2016

The Main Manager Group was committed to producing the design project, develop specific details and its approval from the design concept and then expand to the other levels, as shown below.

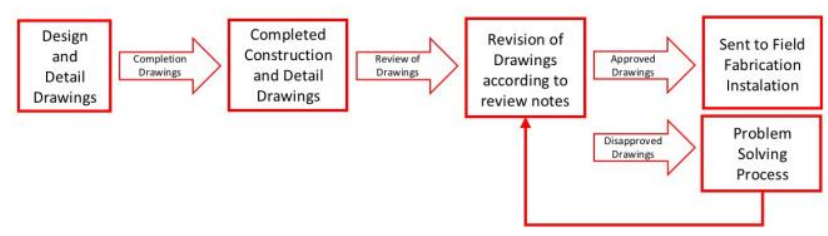

Figure 5: Design process.

From the concept to the production drawings, the approval at least three steps was necessary before it could be used in manufacturing or at the site. The Main Manager has the last word before the manufacturing and the construction, and the Project Manager has to deliver the drawings.

Design Team is committed to developing all details of the architectural design and engineering solution, using BIM system to coordinate all drawings, which are basically three types: (1) Construction drawings included the traditional ones with plans, sections, materials and interfaces with other sectors. (2) The manufacturing drawings are produced from the design manufacturing team according to the architectural design, these are drawings for internal use and requirements profiles, cutting sizes, details, finishing, assembly of components, manufacturing elements and procurement of materials; and (3) Installation drawings are used at the site according to the requirements design, construction and manufacturing drawings, this indicates the marked parts and elements in order to allow the identification, location and connection details. All the drawings and component are identified in each code for better coordination. Periodic meetings are fundamental to synchronize the best solution for several disciplines.

BIM Model is central to coordinate exchange team information and communication in the process, increase collaboration between stakeholders; minimize conflicts, delays, reworks and material waste; reduce contracts, increase safety, performance and reduce financial liability risks; improve labor efficiency; field productivity and quality management; building components are tagged with codes and associated with related information.

The information coordination used is based on several participants with a project communication which contains the main rules to manipulate, upload and download files in an online worldwide cloud platform to be accessed by the authorized key participants. The documents included description, quantity, titles and date; recorded with an imprinted submittal date. An example shown is the choice of junction size for the panels, the architect designer wanted 2 $\mathrm{cm}$ for each panel; manufacturing and structure $4 \mathrm{~cm}$, stating that with this dimension they could guarantee a perfect result. The deal was closed with $3 \mathrm{~cm}$ and required efforts from all participants. This is also a good example of cooperation within the many firms participating in order to construct the same object.

The Construction Management also worked with BIM construction scheduling, auditing quantity survey, production analysis, planned vs. actual analyses, resource balancing, technical supervision, cost control and handover control. In addition to the Constructor Management, three main firms work at the site: the main constructor, with onsite construction, concrete parts; the steel structure company assembling the beams, columns, bracing, curtain walls and stairs and the GRC panels firm, assembling and adapting it. There are other subcontractors for transport, crane, etc.

The Coordination Site is also from a Project Manager firm, which follows the design and management process. The construction methods are analyzed in depth and previously approved, as well as the logistics to use machines, office location, material storage and control. The stored materials in the base area are carried to the construction site with the help of 4D scheduling and construction simulation created with BIM model. All efforts are made for less vehicular traffic, less environmental impact, respecting the supplements needed and ensuring the maximum use of the fair-space. 
Sampling and mockups are developed in different ways: (1) traditional sampling, with the materials and components used; (2) special sampling if necessary using CNC machine from the university partner; (3) Virtual sampling with the 3D Model, to make important assembly decisions, to analyze the performance or aesthetical view; (4) Mockups, specially to verify structural behavior and several envelope panels. This issue is a continuous process along design and construction.

The success of this project is seen especially with the good coordination and collaboration of the entire team, in addition to each enterprise forming a whole; this is helped with personal skills to manage the team and use affordable technological communication system available. This is thanks to the possibility of fast exchange and managing data using the BIM information system, cloud storage data and the internet. The client has been also, with the choice of such a complex organogram, deeply involved in order to set up goal and shorten construction time schedule, avoiding possible delays.

\section{Discussion}

Nowadays the opportunities are focused on different services offered with quality which requires partnerships with enterprises to be competent and reference to the special issues in order to be part of the competitive market, namely: product quality, price, visualizing, personalized capacity and personal relationships and material, design, production and time schedule.

Some criteria, as per the case study, could be not only hard skill i.e. Capacity of data management, BIM advanced personalized tools, international expertise, but also soft skills i.e. collaborative attitude in practice, ability to set objective and goals in relation to scope of works, problem solving attitude due to the unpredictability of complex building construction.

In Industry 4.0, the association in partnership is fundamental to reduce costs, to the customer and projects, provide better services with high quality and low cycle time. To success of building this complex pavilion it was necessary to have available digital cutting-edge equipment and machines, complex communication system and a specialized net collaborator capable to find best solutions.

The context of Business Services using Digital technologies are central tools to make possible the collaboration and coordination of the project of this case study, thanks to internet, automation manufacturing, cloud database, research access and others. Choosing the best partner means to be opened to technical skills, expertise, internal relationships and local understanding. The choice of manufacturers with know-how in their products respond to innovative automated technologies and also the partnership with the managers that in addition to their knowledge, have a good work background and a close relationship with the architects.

The paper shows out preliminarily the necessity to study and better understanding, through case studies, the global supply chain and how companies choose partnership to enable the Industry 4.0.

\section{Acknowledgments}

This research is part of a PhD study, funded by CAPES (Higher Education Personnel Improvement Coordination) and also part of the research group ArqTec (IAU-USP-Brazil) and ActLab (POLIMI-Italy). Sour special thanks to the Engineer Giuseppe Chiarandá, Arch. Omer Check, Arch. Mathia Bravin, Arch. Roberto Naboni, Arch. Luca Beseghelo and Arch.Maya Zheliazkova.

\section{References}

Bartelson, Jens (2010) The social construction of globality, International Political Sociology, v. 4, issue 3, p. 219-235

Biase, Luca de (2015) La Roprogettazione Industriale, in: La Fabrica Digitale: Come Funziona l'industria 4.0 e che cosa ci possiamo fare, Nòva Edu - Lezione di Futuro - 07, II Suo 24 ore.

Cheah, Charles Y. J.; Garvin, Michael J.; Miller, John B. (2004) Empirical study of strategic performance of global construction firms, Journal of Construction and Engineering and Management, v. 130 , issue $11 / 12$, p. $808-818$

Chiprianov, Vanea; Kermarrec, Yvon; Rouvrais, Siegfried; Simonin, Jacques (2014) Extending enterprise architecture modeling languages for domain specificity and collaboration: Application to telecommunication service design, Software and Systems Modeling, v. 13, issue, 13, p. 963-974

Comu, Semra; Taylor, John E.; Messner, John I. (2012) TwoDimensional Globalizing Index and Globalizing Self-Assessment Tool for Engineering and Construction Companies, Journal of Management in Engineering, v. 31, issue 2 p. 2520-2529

Drewer, Stephen (2001) A perspective of the international construction system, Habitat International, v. 25, issue1, p. 69-79

Eom, Shin Jo; Kim, Sang Chul; Jang, Won Suk (2014) Paradigm shift in main contractor-subcontractor partnerships with an eprocurement framework, KSCE Journal of Civil Engineering, v. 19 , issue 7, p. 1951-1961.

EXPO 2015 S.P.A. - MILANO (2012), Theme Guide, TEG Tema working group: Milano, available in:

http://www.czexpo.com/files/expo-milano-theme-quide.pdf.

ACESS: MAY 29, 2016.

Han, Jae-goo; Park, Hwan-pyo; Ock, Jong-ho; Jang, Hyoun-seung (2014) An international competitiveness evaluation model in the global construction industry, v. 19, issue 3, p. 465-477

Han, Seung H.; Kim, Du Y.; Jang, Hyoun S.; Choi, Seokjin (2010) Strategies for contractors to sustain growth in the global construction Market, Habitat International, v. 34, issue 1, p. 1-10

Ibem, Eziyi O.; Laryea, Samuel (2014) Survey of digital technologies in procurement of construction projects, Automation in Construction, V. 46 , p. $11-21$

Kalay, Yehuda E. (2006) The impact of information technology on design methods, products and practices, Design Studies, v. 27, issue 3 , p. 357-380

Larizza, Antonio (2015) La Rinascita della Fabrica: nellera della manifattura digitalizzata, le aziende possono tornare a creare valore a una condizione: L'uomo competere al fianco delle machine. Non contro di esse. In: La Fabrica Digitale: Come Funziona l'industria 4.0 e che cosa ci possiamo fare, Nòva Edu Lezione di Futuro - 07, II Suo 24 ore.

Li, Dan; Eden, Lorraine; Hitt, Michael A.; Ireland, R. Duane (2012) The Architecture of Collaboration, Strategic Management Journal, v. 51, issue 2, p.315-334 
Naboni, Roberto \& PAOLETTI, Ingrid. Advanced Customization in Architectural Design and Construction. Milano: Springer, 2015.

Peressichi, Luigi (2016) Business Service, motore di crescita europea del 2020. In fabrica 4.0: la rivoluzione dela manifattura digitale, come ripensare i processi e i prodotti com i servizi innovativi e tecnologici, Confindustria Servizi Innovativi e Tecnologici.

Potti, Gianni Fabrica 4.0, la nuova rivoluzione è digitale, in fabrica 4.0: la rivoluzione dela manifattura digitale, come ripensare $i$ processi e i prodotti com i servizi innovativi e tecnologici, Confindustria Servizi Innovativi e Tecnologici, 2016.
Rahman, S. H. A., Endut, I. R., Faisol, N., \& Paydar, S. (2014). The Importance of Collaboration in Construction Industry from Contractors' Perspectives. Procedia - Social and Behavioral Sciences, 129 http://doi.org/10.1016/j.sbspro.2014.03.695

Schwab, Klaus (2016) The fourth Industrial Revolution, Genova: World Economics Forum.

Wood, G. D. and Ellis, R. C. T. (2005). "Main contractor experiences of partnering relationships on UK construction projects." Construction Management and Economics, Taylor \& Francis,
Vol.
23,
No.
3 ,
pp.
317-325,
DOI: 